Knowing in interaction: Fieldwork on epistemicity and intersubjectivity

\title{
Exploring Kogi epistemic marking in interactional elicitation tasks: A report from the field
}

Dominique Knuchel (University of Bern)

52nd Annual Meeting of the Societas Linguistica Europaea

21st - 24th August 2019

Leipzig University, Germany 


\section{Outline}

I. Introduction

- The notion of engagement

- Engagement marking in Kogi

II. Interactional elicitation tasks

- Description of stimuli and procedures

- Results and examples

III. Conclusions

IIII. Outlook: Planned elicitation task 


\section{The notion of 'engagement'}

- "A grammatical system for encoding the relative accessibility of an entity or state of affairs to the speaker and addressee"

(Evans et al. 2018)

- Various conceptions of accessibility, i.e. perceptual, epistemic, cognitive (e.g. attention, awareness, knowledge, epistemic rights, expectations...)

- Access to referents or state of affairs

- Intersubjectivity: indication of accessibility to speaker as well as to addressee, as estimated by the speaker

- Epistemicity: distribution of knowledge / epistemic authority 


\section{Joint attention demonstrative}

- One of three demonstratives, first associated with addresseeproximity, reflects attentional contrast

- Example from elicitation:

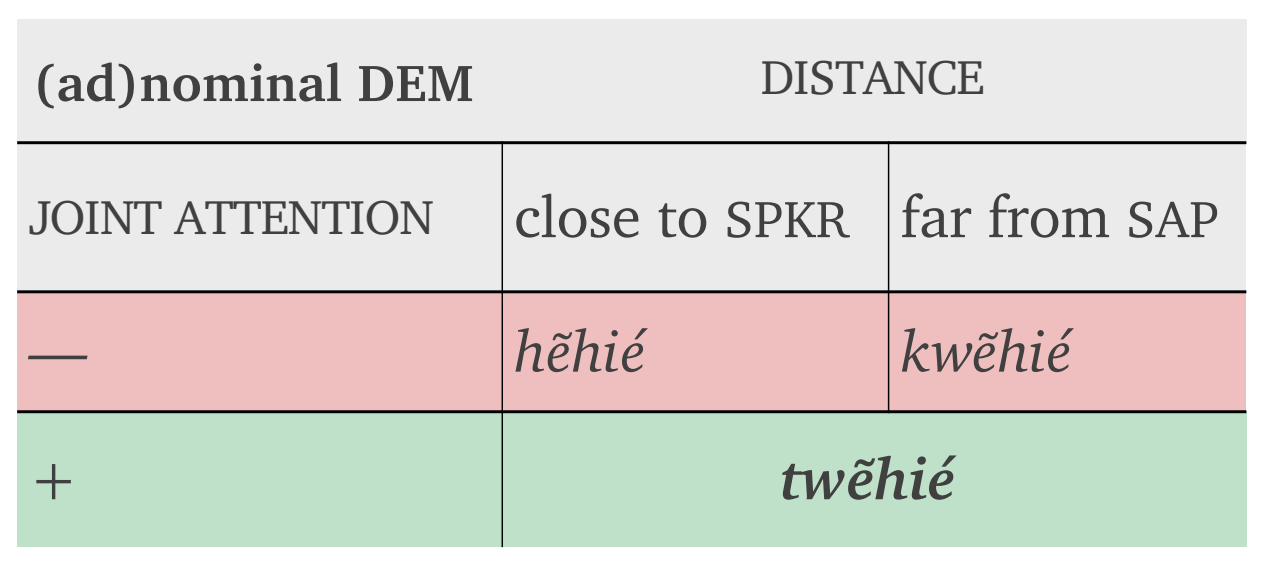
A: Kwẽhié.
'That one over there!
[pointing out one of the objects]
B: Kwẽhié?
'That one over there?'
[checking whether the they have identified the right object]

A: Aha, twẽhié. 'Yes, that one.' [confirming that $\mathrm{B}$ has identified the one A pointed out] 


\section{Joint access demonstrative}

- The use of the form is dependent on a speaker's assumption about the addressee's attentional state

- twẽhié is used, irrespective of distance, to refer to an object that is in the focus of attention of both speaker and addressee

- It cannot be used when joint attention is not yet established

- twẽhié is also used for referents mentioned earlier in discourse > speaker assumes that referent is still accessible to addressee 


\section{Engagement prefixes}

- A set of four verbal prefixes which signal (a)symmetries in access to a state of affairs between speech act participants (Bergqvist 2016)

- Two parameters

- Perspective: whose knowledge/perception is at stake?

- (A)symmetrical access: shared vs. non-shared

\begin{tabular}{|c|c|c|}
\hline & Speaker perspective & Addressee perspective \\
\hline Symmetric & $n i-$ & shi- \\
\hline Asymmetric & $n a(k)-$ & sha- \\
\hline
\end{tabular}




\section{Engagement prefixes}

(1)

hẽhié= ki nahí gamá nzha (ni-ná)

DEM=SW 1SG.POSS bag SPKR.SYM-be

'This is my bag.'

(cnc_el)

(2)

A girl says to her younger brother who mistakenly took her school bag:

nahí nak-ldá!

1SG.POSS SPKR.ASYM-be

'That's mine!'

(obs) 


\section{Characteristics of engagement prefixes}

- Resources for argumentation, negotiation, indicating unexpected information, directing attention, claiming epistemic rights, enquiring about mental states...

- Not obligatory: unmarked/differently marked alternatives

- Used in contexts in which a speaker whishes to epistemically qualify a proposition

- Use is dependent on genre, age / social status of speakers, discourse structure

- Comparable to modal particles (e.g. Germanic languages)

- Semantics/function of such forms is often opaque to speakers 


\section{How to explore engagement in Kogi?}

- ENG forms are infrequent in elicited materials from intial research phase (i.e. translated utterances, elicited narratives either free or stimuli-based)

- Contexts arise in verbal interaction between actual speakers in which (a)symmetries in perceptual/epistemic access exist Ideal data:

- naturally occurring speech

- face-to-face interaction, referring to objects / state of affairs in speech situation

- conversations concerning personal knowledge / experiences / opinions 


\section{How to explore engagement in Kogi?}

- Challenges of obtaining/working with naturally occuring speech...

- Opportunities of interactional, stimuli-based elicitation tasks

- Fairly natural conversational data

- Designed to target certain topics or expressions

- (A)symmetries in access given by task design

- Problem solving that induces verbal negotiation, argumentation, question-answer sequences 


\section{Interactional elicitation tasks}

- Shape Classifier Task

- The Difference Task

- Family Problems Picture Task

- (Positional Verbs matcher-director task [Ameka et al. 1999, Hellwig 2006]) 


\section{Shape Classifier Task}



- Variation of shape classifier task (Seifart 2003)

- Inspired by study on Jahai demonstratives (Burenhult 2003)

- 25 objects of various shapes and sizes, a subset is depicted in picture

- Asymmetrical access: Director has access to pictures, while matcher does not

- Demonstratives, asymmetric prefixes 
Shape Classifier Task

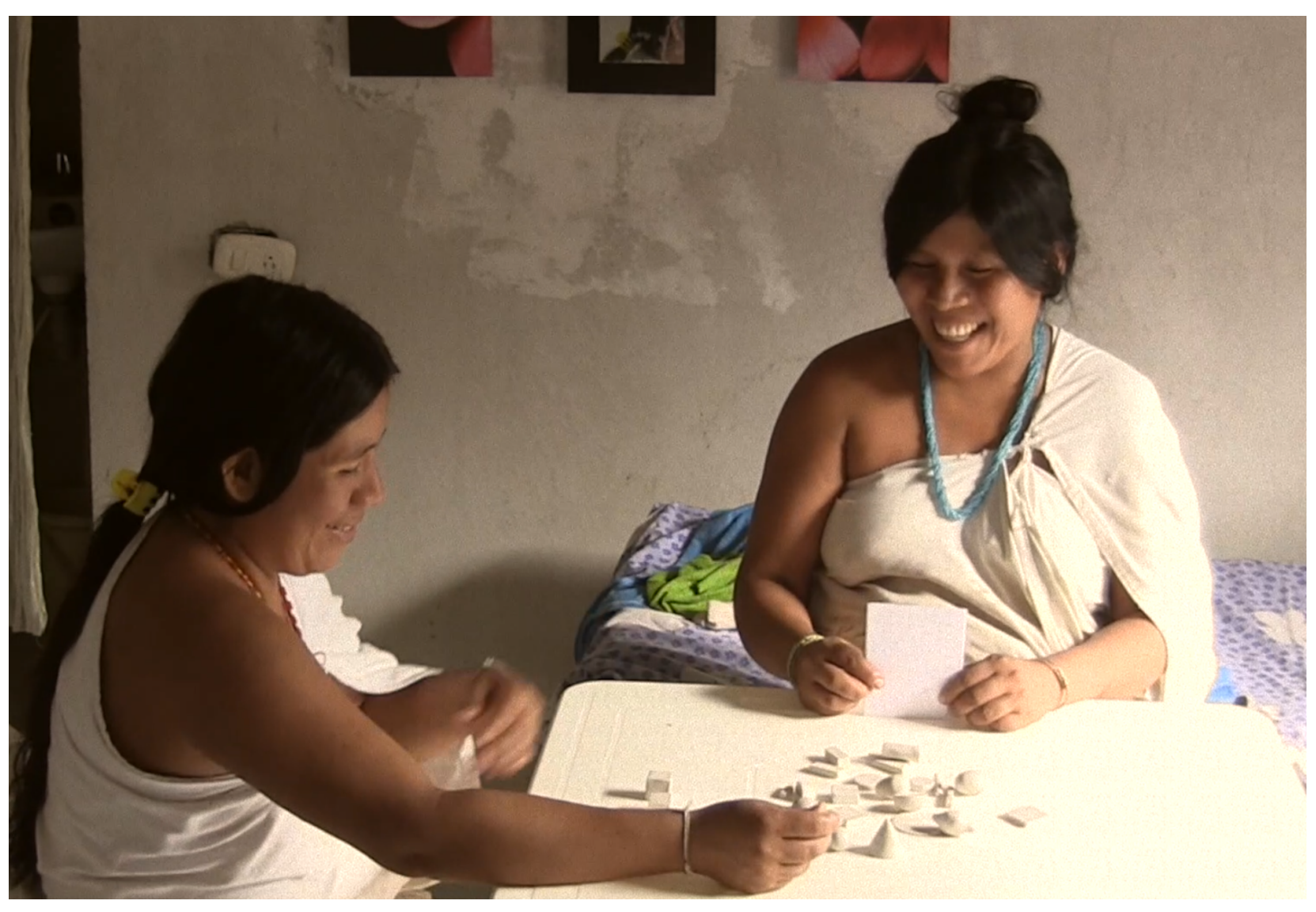




\section{The difference task}

- Based on Enfield \& de Ruiter (2003)

- Original task designed to investigate aspects of multimodal interaction

- 10 Pairs of almost identical picutres

- Participants need to spot the difference

- No interactional asymmetry inherent

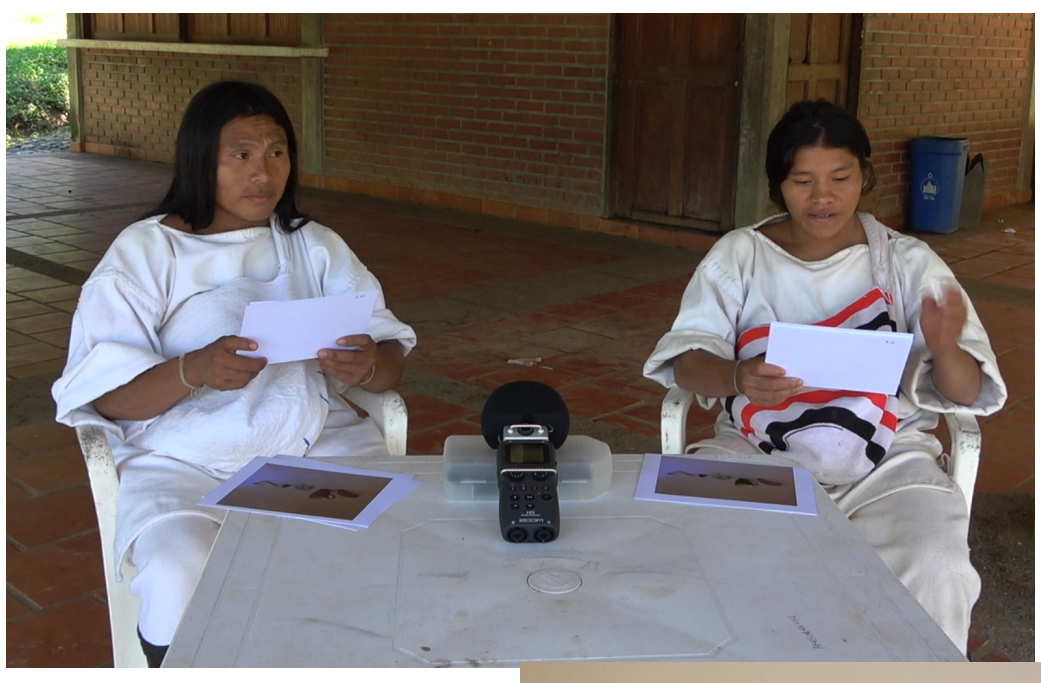
in the director-matcher design

- Symmetric prefixes

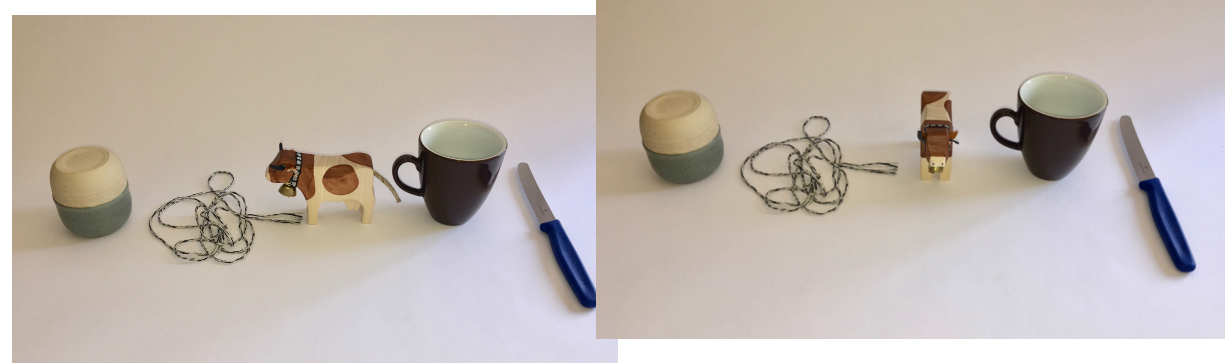


The Family Problems Picture Task

- Collaborative story-building /-telling (San Roque et al. 2012)
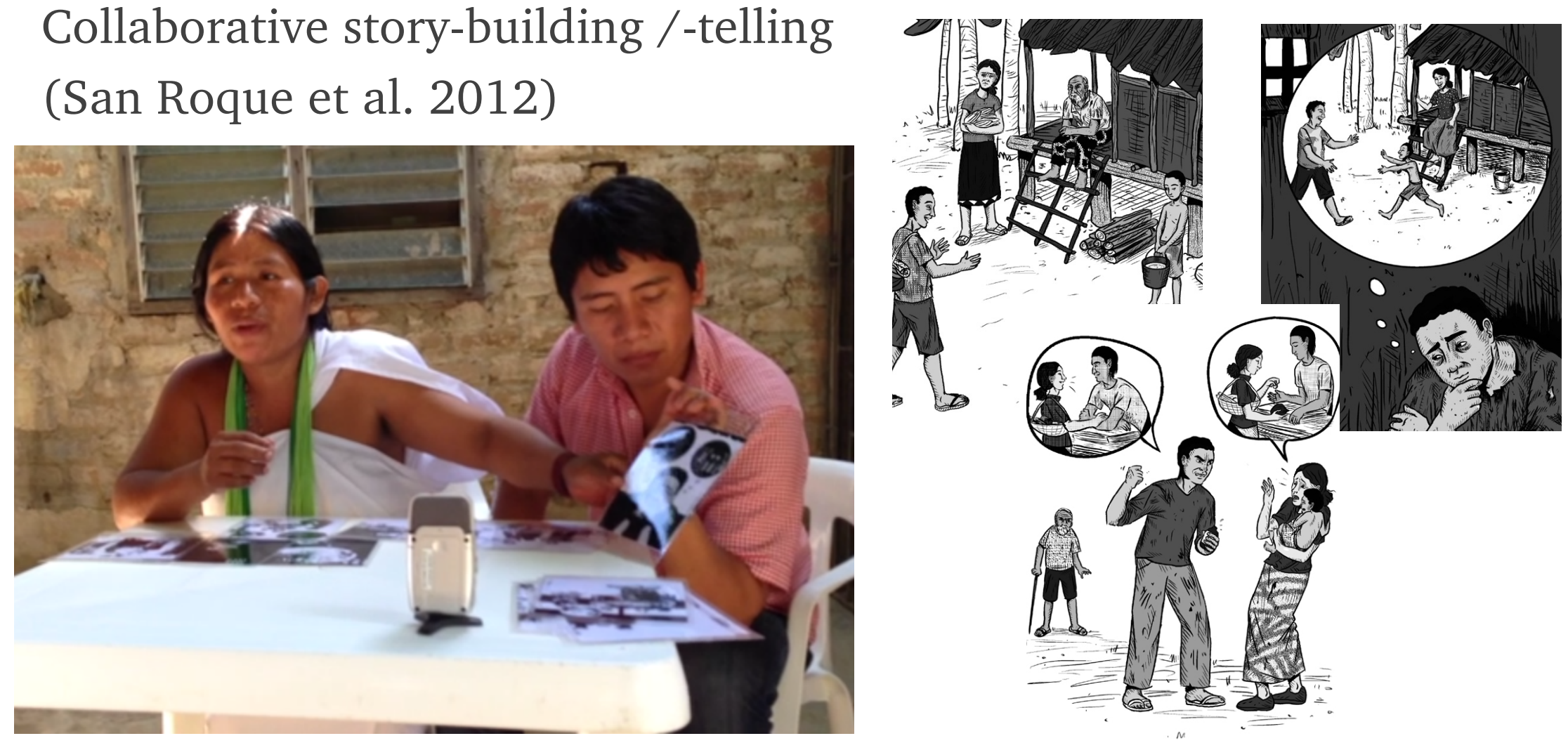


\section{The Family Problems Picture Task}

- Four phases:

I. Description of each picture

II. Organization of cards into a coherent narrative

III. Third-person narrative to an audience

IV. First-person narrative

- Depictions of socially-pregnant and emotionally-charged situations

- The four phases induce different language choices, e.g. descriptions, conversations, narrative discourse, reported speech 


\section{Results}

$>$ Fewer instances of ENG marking than anticipated, yet they are in line with hypotheses

Demonstratives

- Used extensively in the ShaClaTa, to some extent in FPPT

- Evidence for demonstrative that is licensed by joint access

Engagement prefixes

- Only some in matching tasks - no correlation with task design (symmetric vs. asymmetric access to stimuli)

- Most prominent in FPPT, particularly in reported speech 


\section{Example: ShaClaTask}

(3)

D: ezwa ama kẽyakẽyá-gatse naldatshak zumẽya tũ gatse

one uhm edged-seem be.but star look look.like

'One, uhm, with edges but it looks like a star.'

M: kẽyakẽyá gatse naldatshak zumẽya tũ gatse

edged look.like be.but star look look.like

'One with edges but it looks like a star.'

meilde sha-hangu-kú, zumẽya tũ-gatse?

which.one ADDR.ASYM-think-1SG star look-seem

'Which one may it be (lit: I think)? It looks like a star?'

D: hai hẽ nzha (ni-na) ni-hangu-kú hai kẽyakẽyá gatse hai DEM DEM SPKR.SYM.be SPKR.SYM-think-1SG DEM edged look DEM 'Here, it's this one, I think [gestures with lips]. Here, the one with the edges, here.' 


\section{Example: ShaClaTask}

M: kẽyakẽyá-gatse naldachák hui hukase, hẽnié?

edged-seem but house roof, DEM

'With edges but like the roof of a house, this one?'

D: twẽ shi-nalda

DEM ADDR.SYM-be

'Is it that one?'

$\tilde{e}=k i \quad$ makẽwã ak-ldukka ezwa mozhwa twẽe $=k i$ maigwa mechwi

$\mathrm{DEM}=\mathrm{SW}$ four $3 \mathrm{SG}$.IO-be one two $\mathrm{DEM}=\mathrm{SW}$ three only

'This one [in the picture] has four sides, but that one only has three.'

twẽ tũgatse ama tweka mua-ka pa nak-ldo

DEM look-seem uhm DEM middle=LOC be.FLAT SPKR.ASYM-be.located

'It's similar to that one, uhm, it's there in the middle!' 


\section{Example: ShaClaTask}

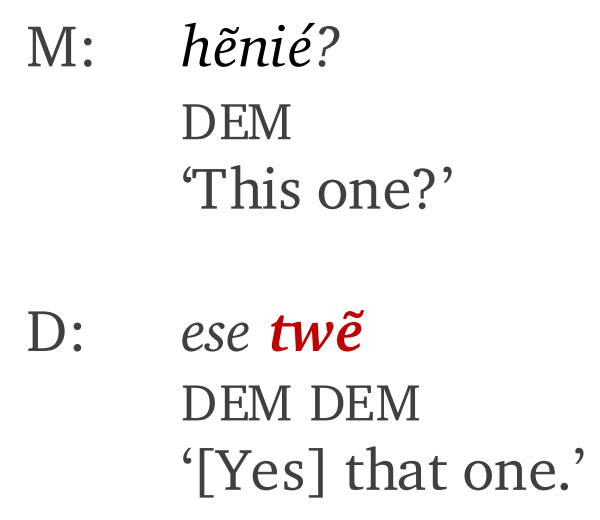




\section{Examples: DiffTask}

(4) hi shi-tũ-kú?

what ADDR.SYM-see-1SG.SUBJ.PRS

'What is it? (lit.: What do I see?)'

(5) malakze hangwa ni-gu-kú

sweet think SKPR.SYM-do-1SG.SUBJ.PRS

'It's candy, I think.'

(LCZ_32) 


\section{Example: DiffTask}

DiffTask (LGN_7-11)

A: $\quad$ bakka zhawa

'A little cow.'

B: $\quad$ mh no inzhi zhawa nakaldini hi zhawa

'No, there's a yuca root, then what?'

A: bakka zhawa

'A little cow.'

B: relo zhawa nenka nakldá [SPKR.ASYM] 'There's a clock!'

A: $\quad$ ah ah baka zhawa

'No, a little cow.'
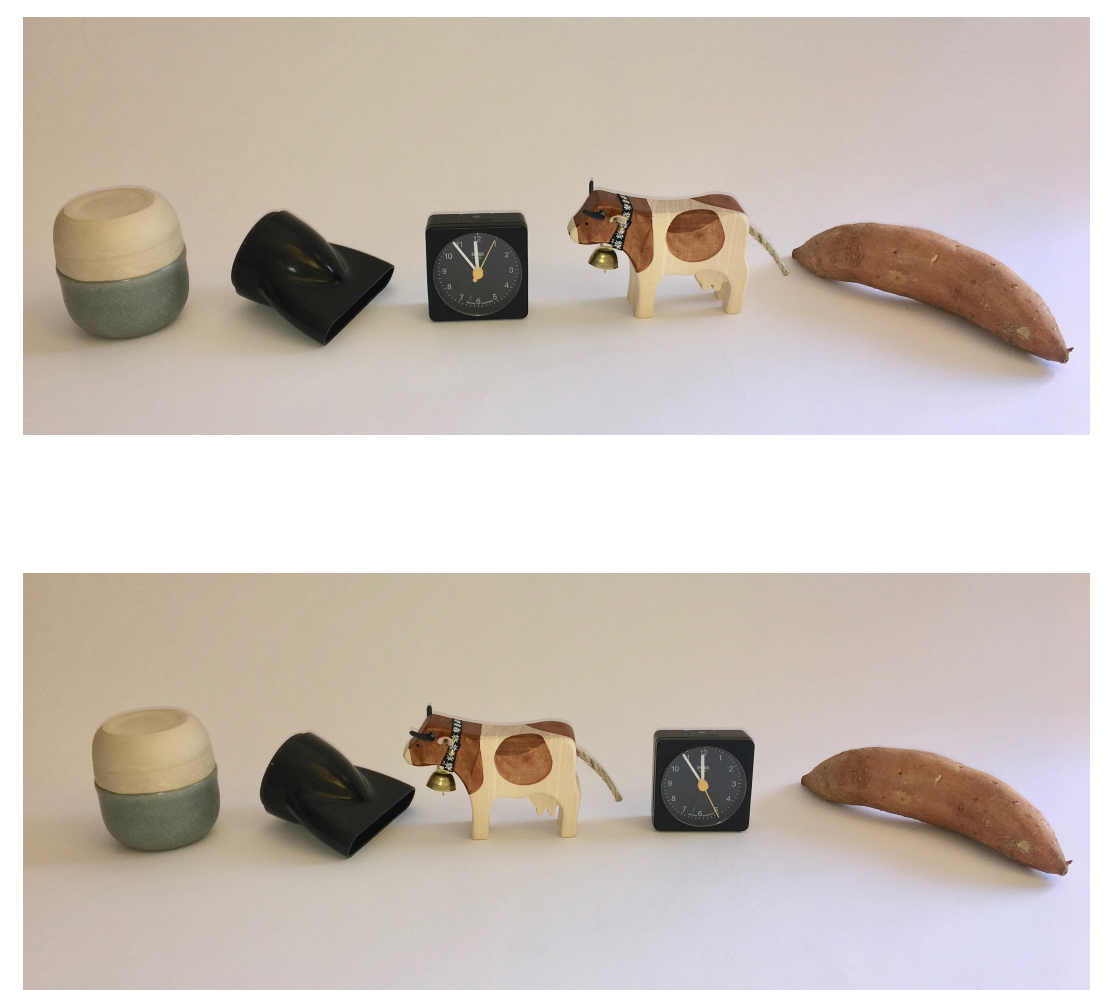


\section{Examples: FPPT}

(5)

heki atshi-ka nak-ldá

mihí

munzhi

DEM do-PRS SPKR.ASYM-be 2SG.POSS woman

ak-bẽya-té

3SG.IOBJ-Say-IPFV

"'This is what your wife does [without you knowing].", he is telling him.' (fppt1-1_cnc)

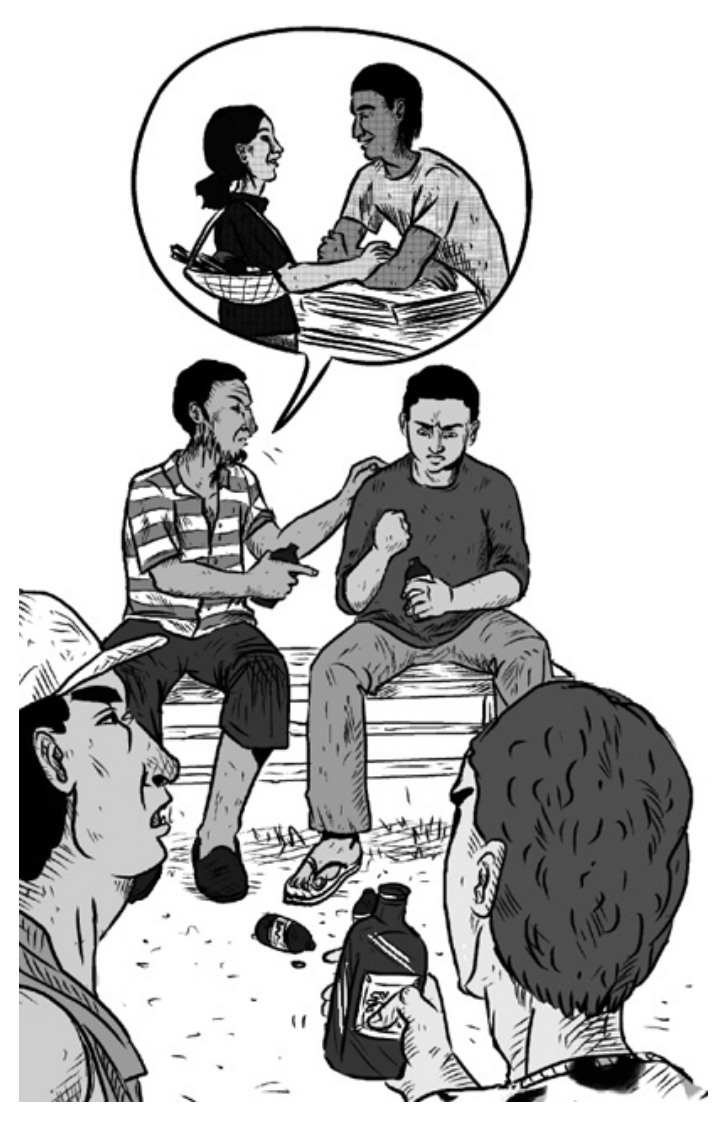




\section{Examples: FPPT}

(3)

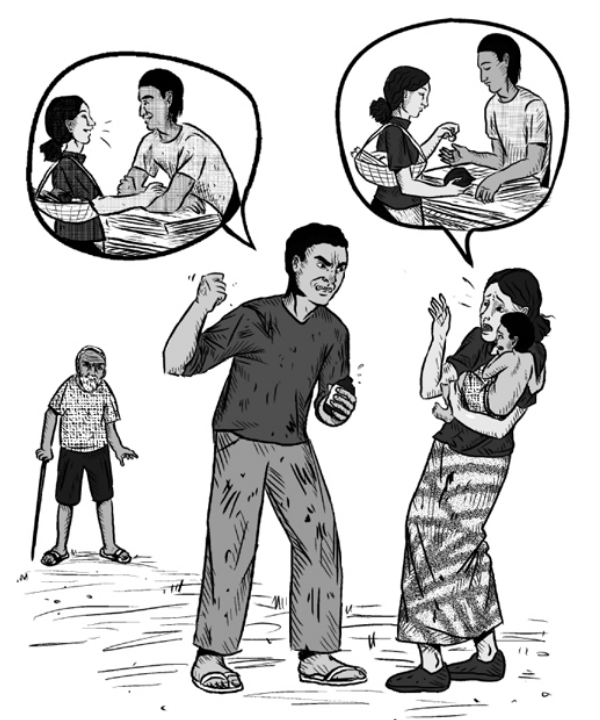

ekí sigí na ma-wa-tũ-ne

DEM.ADV man with 2SG.DO-3PL.SJ-see-PST

nag-a-bẽ-ne nalda shã (shi-na)

1SG.IO-3PL.SJ-tell-PST be ADDR.SYM.be

[Man:] 'They saw you like this with another man, is that so?.'

(fppt1-3_cnc)

no z-häbbia-l nuka ne-nuge nzha (ni-na)

no INTR-buy-PURP only go-1SG.PST SPKR.SYM.be

[Woman:] 'No, I just went to buy [something].' 


\section{Conclusions}

- Fewer instances of ENG marking than anticipated, yet they are in line with hypotheses

- Evidence for joint access demonstrative in ShaClaTa

- Instances of ENG prefixes in contexts of convincing, unexpected information, disputes

- Use of ENG prefixes in reported conversations (FPPT)

- Limitations

- Naturalistic interactions, yet artifical setting / topics

- Low frequency of ENG markers due to low personal investment in and low complexity of matching tasks 


\section{Outlook}
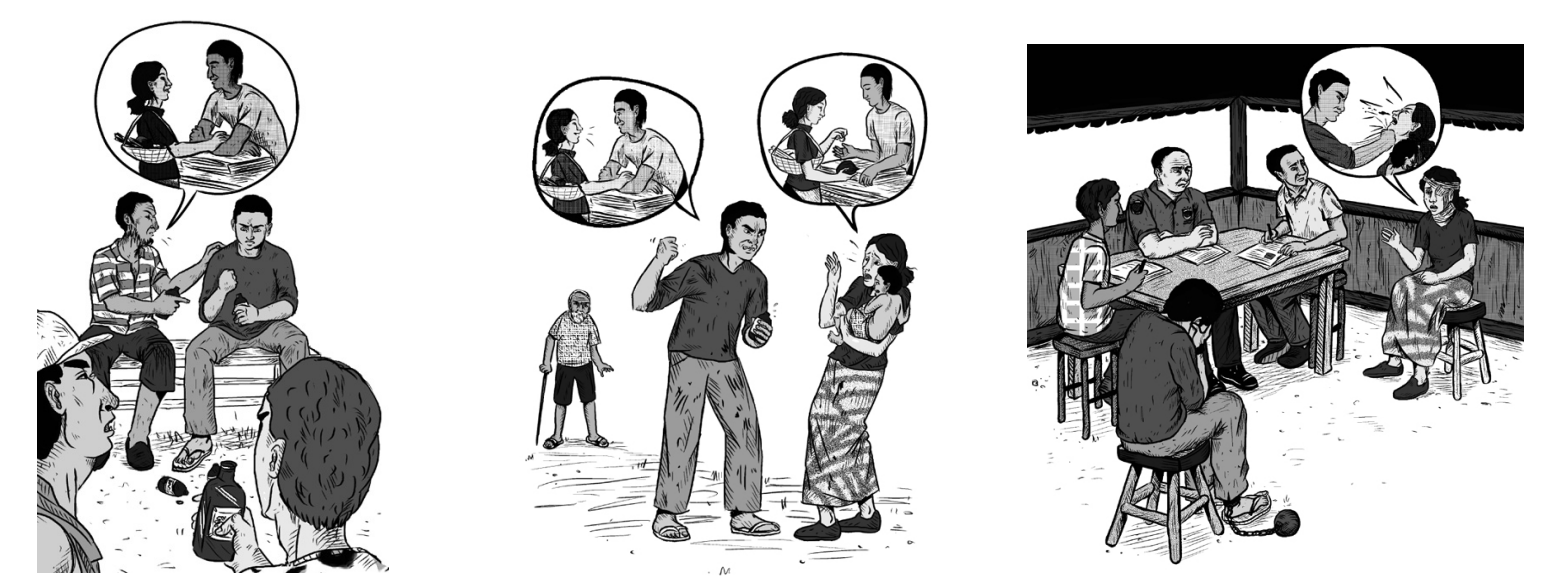

- ENG markers in reported conversations

- Contexts of gossip, arguments, accusation 


\section{Outlook}

- Planned interactional elicitation task based on Senft (2003) "Reasoning in language"

- Original task investigates how speakers "verbally reason about moral issues"

- Moral problems presented in open story plots or scenarios that require a solution

- Plots are aimed to present common conflicts in societies and human behaviour

- Discussion about personal opinions and social norms 


\section{Outlook}

- Stimuli: Unfinished short stories / descriptions of problems

- Participants: Native speaker interviewer, and at least two speakers

- Procedure: Interviewer presents scenario, solicits discussion of possible outcome/solution and imagined conversations 


\section{References}

Ameka, Felix, Carlien de Witte \& David Wilkins. 1999. Picture series for positional verbs: Eliciting the verbal component in locative descriptions. In David Wilkins (ed.), Manual for the 1999 Field Season, 48-54. Nijmegen: Max Planck Institute for Psycholinguistics.

Bergqvist, Henrik. 2016. Complex epistemic perspective in Kogi (Arwako). International Journal of American Linguistics 82(1), 1-34.

Burenhult, Niclas. 2003. Attention, accessibility, and the addressee: The case of the Jahai demonstrative ton. Pragmatics 13, 363-379.

Enfield, N. J., \& De Ruiter, J. P. (2003). The diff-task: A symmetrical dyadic multimodal interaction task. In N. J. Enfield (Ed.), Field research manual 2003, part I: Multimodal interaction, space, event representation (pp. 17-21). Nijmegen: Max Planck Institute

Evans, Nicholas, Henrik Bergqvist \& Lila San Roque. 2018a. The grammar of engagement I: framework and initial exemplification. Language and Cognition 10(1). 110-140.

Evans, Nicholas, Henrik Bergqvist \& Lila San Roque. 2018b. The grammar of engagement II: typology and diachrony. Language and Cognition 10(1). 141-170. 


\section{References}

Hellwig, Birgit. 2006. Field semantics and grammar-writing: Stimuli-based techniques and the study of locative verbs. In Ameka, Felix, Alan Dench, Nicholas Evans (eds.) Catching language: The standing challenge of grammar writing. Berlin, New York: de Gruyter. 321-358.

Özyürek, Asli and Sotaro Kita. n.d. Joint attention and distance in the semantics of Turkish and Japanese demonstrative systems.

San Roque, L., Gawne, L., Hoenigman, D., Miller, J. C., Rumsey, A., Spronck, S., ... \& Evans, N. 2012. Getting the story straight: Language fieldwork using a narrative problem-solving task. Language Documentation \& Conservation, 6.

Seifart, Frank. 2003. Encoding shape: Formal means and semantic distinctions. In: Nick Enfield (ed.). Field research manual 2003 part I: Multimodal interaction, space, event representation. Nijmegen: Max Planck Institute for Psycholinguistics. 57-59. 